\title{
The choice of efficiency benchmarking metric in evaluating firm productivity and viability
}

\author{
S. C. West $\mathbb{D}^{1} \cdot$ A. W. Mugera $\mathbb{D}^{1} \cdot$ R. S. Kingwell $\mathbb{D}^{1,2}$
}

Accepted: 20 January 2022 / Published online: 9 February 2022

(c) The Author(s) 2022

\begin{abstract}
The Debreu-Farrell measure of technical efficiency is widely used to benchmark firm performance. A limitation of this measure is that it is orientation restricted and evaluates the performance of a decision-making unit in an explicit direction relative to the best-practice frontier and not the most productive point on the frontier. Therefore, the measure does not provide policy insight on how to direct decision-making units to achieve the best possible productivity level. Taking a departure from conventional nonparametric benchmarking studies, this study benchmarks the performance of commercial farm businesses in the Western Australia's wheatbelt region using total factor productivity efficiency ('TFP efficiency') and compares the results to those when the conventional technical efficiency measures are applied. We find that the two measures of firm performance differ and are influenced by different sources of firm heterogeneity. Therefore, derived policy insights and prescriptions also differ. This is an important insight that policymakers and practitioners need to be aware of.
\end{abstract}

Keywords Total factor productivity efficiency $\cdot$ Technical efficiency $\cdot$ Performance benchmarking $\cdot$ Agriculture

JEL codes $\mathrm{C} 14 \cdot \mathrm{C} 43 \cdot \mathrm{D} 24 \cdot \mathrm{L} 21 \cdot \mathrm{Q} 12$

\section{Introduction}

Agricultural productivity growth is essential for feeding the world's growing population, improving food security, and lessening the need to bring virgin land into agricultural production (ERS 2019). Globally, there are wide geographical variations in both crop and livestock productivity, even in regions that experience similar climates. Agricultural scientists and policymakers have been interested in understanding what interventions or policies can be used to eliminate mistakes in production given available production technologies and management practices. Low agricultural

Supplementary information The online version contains supplementary material available at https://doi.org/10.1007/s11123022-00628-1.

S. C. West

scw.economics@gmail.com

1 The UWA Institute of Agriculture, University of Western Australia, Crawley, WA, Australia

2 Australian Export Grains Innovation Centre, Perth, WA, Australia productivity may occur because of both institutional, technical and economic constraints, as illustrated by numerous studies that have sought to understand the main drivers of agricultural productivity (Julien et al. 2019; Scheiterle et al. 2019; Key 2019; Rada and Fuglie 2019; Thompson et al. 2019; Khan et al. 2019; Komarek and Msangi 2019; Kaila and Tarp 2019; Nordjo and Adjasi 2019; Rada et al. 2020; Chambers et al. 2020). Indeed, productivity and efficiency analysis has emerged as a key subfield in agricultural production. From a policy perspective, understanding how and why productivity and efficiency vary across farm businesses and regions is essential to aid in the design of policies that promote competitiveness and viability.

Technical efficiency is a benchmarking metric that measures how effectively input resources are used to produce output given the prevailing production technology. A decision-making unit is input-oriented technically inefficient if it is technically possible to use a lesser bundle of inputs to produce the given output bundle; it is outputoriented technically inefficient if a higher bundle of output is technically attainable for the given input bundle. In a nonparametric approach, technical efficiency is widely used to evaluate the performance of decision-making units in an 
explicit direction relative to points on the best-practice frontier and regressed against selected covariates to investigate sources of farm performance heterogeneity. This is a common practice both in developed (Silva and Stefanou 2007; Emvalomatis et al. 2011; Latruffe and Nauges 2014; Qushim et al. 2016; Lambarraa et al. 2016; Abdul-Salam and Phimister 2017; Latruffe et al. 2017; Skevas et al. 2018b; Kostov et al. 2019; Roll 2019; Gadanakis et al. 2020; Bonfiglio et al. 2020) and developing countries (Chavas et al. 2005; Solís et al. 2009; Shee and Stefanou 2015; Murtaza and Thapa 2017; Pede et al. 2018; Lawin and Tamini 2019; Mishra et al. 2019, 2020; Adamie et al. 2019). Despite its extensive use as a measure of managerial performance by researchers and policymakers, technical efficiency only compares a decision-making unit's performance by a vertical expansion (output-orientation) or horizontal contraction (input-orientation) in the direction of the best-practice frontier; it does not necessarily provide insight into the firm's performance relative to the position where its productivity is maximised.

An alternative measure for performance benchmarking is the total factor productivity (TFP) efficiency metric associated with O'Donnell $(2008,2016)$. This metric measures the extent to which a decision-making unit falls short from attaining the best possible productivity in each production period. The advantage of this metric is that it can be computed using TFP indices that are transitive. Therefore, TFP efficiency can be used to provide multilateral and multitemporal comparisons of firm performance. Owing to its multiplicative completeness (O'Donnell 2016, 2018), prior studies that have estimated TFP efficiency have done so exclusively for the purpose of decomposing it into different efficiency measures (Oude Lansink et al. 2000; Giannakas et al. 2001; Brümmer et al. 2002; Karagiannis et al. 2004; Newman and Matthews 2006; Atsbeha et al. 2017; Islam et al. 2014; Mugera et al. 2016; O'Donnell 2016; Darku et al. 2016; Dakpo et al. 2018; Ang 2019). TFP efficiency, unlike conventional technical efficiency, is not orientation restricted, i.e., it is not estimated from an output or input-oriented perspective (O'Donnell 2008). Despite these differences and their implications on how researchers and policymakers use empirical results of performance benchmarking to design policies to improve productivity and overall competitiveness of enterprises, no study has sought to clearly differentiate between TFP efficiency and technical efficiency as measures of firm managerial performance and investigate whether they are influenced by similar sources of firm heterogeneity.

This study investigates how the choice of metric for performance benchmarking, i.e., either TFP efficiency or conventional technical efficiency, affects the empirical results and policy implications deduced from analysis. We use a balanced panel data of 64 broadacre mixed enterprise farm businesses in Western Australia's Wheatbelt region as a case study to show that a firm can be technically efficient but not necessarily TFP efficient, with the implication that elimination of technical inefficiency may not necessarily imply improving total factor productivity. The study shows that factors contributing to variability in technical efficiency may not contribute to variability in TFP efficiency across farms, implying that policy measures derived from estimates of determinants of technical efficiency may not necessarily be relevant for designing policies to improve farm productivity and competitiveness. This insight has broader implication for performance benchmarking of decision-making units in the non-agricultural sectors of the economy.

To the best of the authors' knowledge, this is the first study to contrast TFP efficiency and orientation-specific technical efficiency as measures of firm performance. This study extends the literature on efficiency and performance benchmarking by highlighting the benefits of TFP efficiency as a performance benchmarking metric and the implications of this to policymakers and management practitioners seeking to enhance enterprise viability and competitiveness. This type of analysis is important in understanding which management practices and policy measures are associated with higher levels of efficiency and productivity.

\section{Comparing concepts of efficiency}

In the context of a multiple-input and multiple-output production system, let firm $i$ with a given production technology $T$ at time $t$ use a vector of inputs, $\mathbf{x}_{i t} \in \Re_{+}^{M}$, to produce a vector of outputs, $\mathbf{q}_{i t} \in \Re_{+}^{N}$. In the absence of environmental variables, the production technology of an industry may be defined by the production possibility set (Balk 1998):

$$
T=\{(\boldsymbol{x}, \boldsymbol{q}): \boldsymbol{x} \text { can produce } \boldsymbol{q}\}
$$

Using the individual input and output vectors, aggregated inputs, $\left(X_{i t} \equiv X\left(x_{i t}\right)\right)$ and aggregated outputs, $\left(Q_{i t} \equiv Q\left(q_{i t}\right)\right)$ can be estimated subject to the aggregator functions being nonnegative, non-decreasing and linearly homogenous. The aggregate functions can be computed using various aggregation methods (O'Donnell 2016). The ratio of aggregate output to aggregate input is the measure of total factor productivity (O'Donnell 2008):

$$
T F P_{i t}=\frac{Q_{i t}}{X_{i t}}
$$

The computed TFP metric can be decomposed into the maximum observable TFP in each production period $\left(T F P_{t}^{*}\right)^{1}$ and TFP efficiency $\left(T F P E_{i t}\right)$, which is the ratio of

\footnotetext{
1 The maximum observable TFP may or may not be achieved by one or more producers in each production period (O'Donnell 2018).
} 
the TFP of a specific producer $i$ in period $t$ relative to the maximum observable TFP in the period (O'Donnell 2012b):

$T F P_{i t}=T F P_{t}^{*} \times T F P E_{i t}=T F P_{t}^{*} \times \frac{T F P_{i t}}{T F P_{t}^{*}}$

Total factor productivity efficiency can be viewed as a measure of the overall productive efficiency of a producer given the prevailing production technology. Measured in levels, TFP efficiency provides an estimate of the ratio of the TFP of a decision-making unit and the maximum attainable TFP in a given production period.

Figure 1 shows six producers, A, B, C, D, E, and F. Producer A both output-oriented and input-oriented technically inefficient. Subject to the assumptions of a common production environment and a mix-restricted production possibility set, whereby the production possibility set only contains aggregates of input and output vectors that may be written as scalar multiples of the input and output vectors at point A, producer A can use available aggregate input $X_{A t}$ to expand its aggregate output to that of producer $\mathrm{C}$, who sits on the variable return to scale mix-restricted production frontier with an output of $Q_{C t}$. The output-oriented technical efficiency of producer A may be expressed as the ratio of the distances $X_{A t} Q_{A t}$ over $X_{A t} Q_{D t}$. Alternately, to produce the same output of $Q_{A t}$, producer A could reduce its aggregate input to that of producer $\mathrm{F}, X_{F}$, who like producer $\mathrm{C}$, is technically efficient since they sit on the mix restricted variable returns to scale production frontier. The inputoriented technical efficiency of producer A may be expressed as the ratio of the distance $Q_{A t} X_{F t}$ over the distance $Q_{A t} X_{A t}$.

Although producers $\mathrm{F}$ and $\mathrm{C}$ are technically efficient, they are neither mix nor scale efficient. Scale efficiency is computed as the ratio of a producer's technical efficiency under a constant return to scale production function to its technical efficiency under a variable return to scale production function. Subject to the imposed mix restriction, producer $\mathrm{C}$ would become scale efficient by reducing its aggregate input to $X_{E t}$ and its aggregate output to $Q_{E}$, as observed in the case of producer $\mathrm{E}$ that is located at the point of tangency between the mix restricted constant and variable returns to scale production functions. Mix efficiency is measured as the ratio of the aggregate output on the mix restricted frontier over the aggregate output on the mix unrestricted frontier that uses a common aggregate input, with the mix unrestricted frontier being the boundary of all technically feasible input-output combinations regardless of input and output mix (O'Donnell 2011). By relaxing the assumption of restricted mix, the maximum potential production using $X_{A t}$ may be expanded from $Q_{C t}$ to $Q_{D t}$. Producer D is both mix and technically efficient but is not scale efficient.

The point that is mix, scale and technically efficient occurs at the tangency between the constant returns to scale

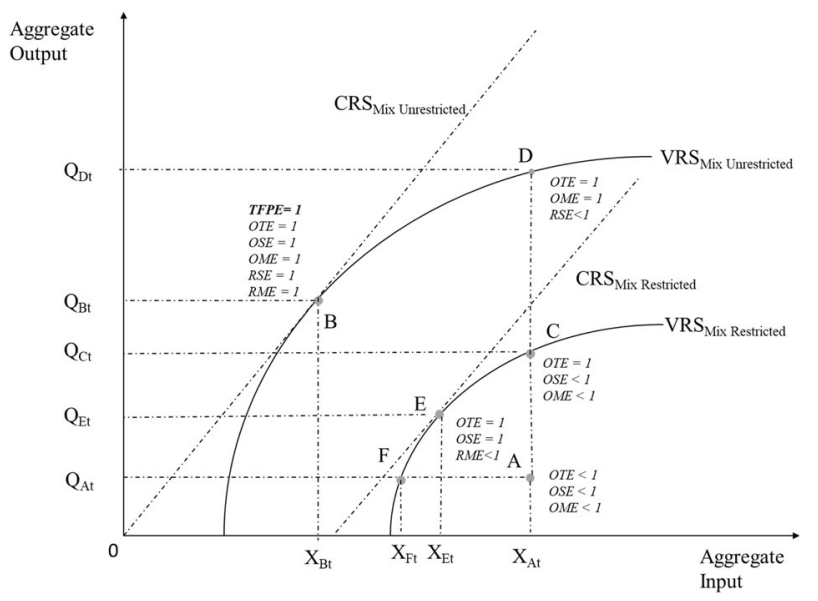

Fig. 1 Efficiency concepts (O’Donnell 2008)

and variable returns to scale mix unrestricted production frontiers, which is where producer B sits. This is the point where TFP is at its maximum. Therefore, a producer (as is the case with producers $\mathrm{C}, \mathrm{D}, \mathrm{E}$, and F) can be technically efficient but not TFP efficient.

To understand why the differences between TFP efficiency and technical efficiency are relevant to both policymakers and producers in the analysis of enterprise viability, consider the decomposition of profitability (the ratio of aggregate revenues to aggregate costs) offered by O'Donnell (2012a, b) and investigated by Mugera et al. (2016):

$P R O F_{i t}=T F P_{i t} \times T T_{i t}$

Equation 4 shows that profitability $P R O F_{i t}$ can be decomposed into TFP and Terms of Trade $\left(T T_{i t}\right)$, which is calculated as the ratio of an aggregate of prices received by a producer over an aggregate of the prices paid. Restating Eq. 4 using Eq. 3:

$$
P R O F_{i t}=T F P_{t}^{*} \times T F P E_{i t} \times T T_{i t}
$$

In the presence of perfectly competitive markets where all producers are price takers and have access to same production technology Eq. 5 can be restated as $P R O F_{i t}=$ $\kappa_{t} T F P E_{i t}$ given $\kappa_{t}=T T_{t} \times T F P_{t}^{*}$. This suggests that in the long term, and under the assumption that producers are profit-maximising, policymakers should aim to assist producers to maximise TFP efficiency, as this is the only component measure of profitability that the individual farm businesses can influence.

As previously stated, TFP efficiency can be decomposed into different measures of efficiency because of its multiplicative completeness (see recent examples from O'Donnell 2016, Darku et al. 2016; Skevas et al. 2018a; Njuki et al. 2018; Rada et al. 2019). For illustrative purposes, a 
widely adopted decomposition approach, proposed by O'Donnell (2012a), is provided in Eqs. 6a and 6b:

$$
\begin{aligned}
& T F P E_{i t}=O T E_{i t} \times O S E_{i t} \times R M E_{i t} \\
& T F P E_{i t}=I T E_{i t} \times I S E_{i t} \times R M E_{i t}
\end{aligned}
$$

In Eq. 6a, OTE is a measure of output-oriented mix restricted technical efficiency, OSE is output-oriented scale efficiency, and $R M E$ is residual mix efficiency, which is a measure of productive performance associated with economies of scope and provides a measure of the difference between TFP at the point of mix-invariant optimal scale and TFP at the point of maximum productivity (O'Donnell 2010). From Fig. 1, RME is the ratio $\frac{Q_{E t} / X_{E t}}{Q_{B t} / X_{B t}}$, where producer $\mathrm{E}$ is both technically and scale efficient but mix inefficient. Equation $6 \mathrm{~b}$ provides corresponding efficiency measures from an input-orientation. Therefore, TFP efficiency is a more complete measure of efficiency compared to the conventional technical efficiency for policy analysis and design. O'Donnell (2018) refers to TFPE as the technical, scale, and mix efficiency (TSME) measure. By contrasting the location of the TFP efficient point on the mix unrestricted production frontier and the location of the technically efficient point on the mix restricted frontier, TFP efficiency provides insight into production rigidities and fixed structures that are not discernible from technical efficiency estimates.

Consider a scenario where a regulator chooses to implement a policy that seeks to reduce barriers to credit access through regulatory change that promotes debt use to invest in agricultural technology (e.g., disc seeding for zero tillage) and reduce technical inefficiency in crop production. This policy, however, may cause farm businesses to increase their scale of operations beyond their optimal size resulting in scale inefficiency and mix inefficiencies. These inefficiencies may contribute to low overall production efficiency (i.e., TFP efficiency), which may ultimately reduce TFP, profitability and viability of a farm business.

\section{Estimation of efficiency measures}

\subsection{Total factor productivity efficiency estimation}

In the absence of output and input price information, this study uses the Färe-Primont aggregation method to estimate $Q$ and $X$ (O'Donnell 2011). Assuming the production possibility set from Eq. 1 is subject to weak regularity conditions, the computation of the Färe-Primont aggregators requires estimation of an output-oriented distance function and an input-oriented distance function (Eqs. 7a and 7b) to solve for unknown nonnegative parameters $\alpha, \beta, \varphi$, and $\eta$, as well as the intercept terms that are used to estimate the input and output shadow prices (O’Donnell 2010, 2011)2

$$
\begin{gathered}
D_{O}\left(\boldsymbol{x}_{0}, \boldsymbol{q}_{0}, t_{0}\right)^{-1}=\min _{\alpha, \gamma, \beta} \gamma+x_{0}^{\prime} \beta \\
\text { s.t. } \\
\gamma l+X^{\prime} \beta \geq Q^{\prime} \alpha \\
q_{0}^{\prime} \alpha=1 \\
\alpha \geq 0 \\
\beta \geq 0 \\
D_{O}\left(\boldsymbol{x}_{0}, \boldsymbol{q}_{0}, t_{0}\right)^{-1}=\max _{\phi, \delta, \eta} q_{0}^{\prime} \phi-\delta: \\
\text { s.t. } \\
Q^{\prime} \phi \leq \delta l+X^{\prime} \eta \\
x_{0}^{\prime} \eta=1 \\
\phi \geq 0 \\
\eta \geq 0
\end{gathered}
$$

In the above equations, $l$ is the unit vector, $\boldsymbol{x}_{0}$ is the vector of $J$ inputs (i.e., $\left[x_{0_{1}}, x_{0_{2}}, \ldots, x_{0_{J}}\right]$ ), and $\boldsymbol{q}_{0}$ is the vector of $K$ outputs (i.e., $\left[q_{01}, q_{02}, \ldots, q_{0 j}\right]$ ) for the base case firm 0 . Subject to the presence of $M$ decision-making firms, $X$ is a $M \times J$ matrix of all inputs used in production period $t_{0}$ and $Q$ is a $M \times K$ matrix of outputs produced in the same period.

The derivatives of the output and input distance functions with respect to outputs and inputs (Eqs. 7a and 7b) are the revenue and cost-deflated output and input shadow prices $(\boldsymbol{p}$ and $\boldsymbol{w})$. In the case of the Färe-Primont index, the derivatives must be evaluated relative to the distance functions of the base case production unit $D_{O}\left(\boldsymbol{x}_{0}, \boldsymbol{q}_{0}, t_{0}\right)$ and $D_{I}\left(\boldsymbol{x}_{0}, \boldsymbol{q}_{0}, t_{0}\right)$ (O’Donnell 2011; Baráth and Fertó 2017):

$\boldsymbol{p}_{0}^{*}=\frac{\delta D_{O}\left(\boldsymbol{x}_{0}, \boldsymbol{q}_{0}, t_{0}\right)}{\delta \boldsymbol{q}_{0}}=\frac{\left(\alpha_{0}\right)}{\left(\gamma_{0}+\boldsymbol{x}_{0}^{\prime} \beta_{0}\right)}$

$\boldsymbol{w}_{0}^{*}=\frac{\delta D_{I}\left(\boldsymbol{x}_{0}, \boldsymbol{q}_{0}, t_{0}\right)}{\delta \boldsymbol{x}_{0}}=\frac{\left(\eta_{0}\right)}{\left(\boldsymbol{q}_{0}^{\prime} \phi_{0}-\delta_{0}\right)}$

The aggregate output $\left(Q_{i t}\right)$ and input $\left(X_{i t}\right)$ are solved for firm $i$ in each period $t$ as follows:

$Q_{i t}=\boldsymbol{q}_{i t}^{\prime} \boldsymbol{p}_{0}^{*}=\boldsymbol{q}_{i t}^{\prime} \frac{\left(\alpha_{0}\right)}{\left(\gamma_{0}+\boldsymbol{x}_{0}^{\prime} \beta_{0}\right)}$

$X_{i t}=\boldsymbol{x}_{i t}^{\prime} \boldsymbol{w}_{0}^{*}=\boldsymbol{x}_{i t}^{\prime} \frac{\left(\eta_{0}\right)}{\left(\boldsymbol{q}_{0}^{\prime} \phi_{0}-\delta_{0}\right)}$

The use of common shadow prices $\boldsymbol{p}_{0}^{*}$ and $\boldsymbol{w}_{0}^{*}$ to construct the output and input aggregators implies that the output and

\footnotetext{
${ }^{2}$ The production technology function is estimated in this study without an allowance for the possibility of technological regress under and both variable returns to scale and constant returns to scale. The assumption of no technological regress means that we have assumed that technology (know-how and equipment) available to firms did not decline (or 'disappear') or decay over the study period.
} 
input of different firms in different periods are constructed relative to a common base case. Therefore, unlike other aggregators, the Färe-Primont aggregators allow for the comparison of cardinal TFP estimates both within and across periods. Restated, the Färe-Primont aggregator satisfies the transitivity axiom whereby, for example, the direct comparison of the input index of a firm $i$ in two periods $(t$ and $t+2)$ yields the same input change as an indirect comparison through a third period $X(t, t+2)=X(t, t+1) \times X(t+1, t+2)$ (O'Donnell $2012 \mathrm{a}, \mathrm{b})$. The same applies for the output aggregator. Thus, the computed TFP measures are also transitive and allow for inter-temporal comparison of relative firm performance over time (per Eq. 3).

\subsection{Technical efficiency estimation}

This study uses the widely adopted radial Debreu-Farrell input and output based measures (Debreu 1951; Farrell 1957) to estimate technical efficiency. From a production frontier perspective, output-oriented technical efficiency is a measure of the proportional expansion of outputs required to vertically move an inefficient producer to the production possibility frontier without a change in input levels. The input-oriented technical efficiency is a measure of the proportional reduction in inputs needed to horizontally move an inefficient producer to the production possibility frontier without a change in output level. The measures are solved for using the linear programming technique specified in Eqs. 10 and 11 subject to a variable returns to scale technology:

$$
\begin{gathered}
\widehat{F}_{i}^{O}\left(q_{i}, x_{i}, q, x \mid V R S\right)=\max _{z, \theta} \theta \\
\text { s.t. } \\
\sum_{i=1}^{N} z_{i} q_{i n} \geq \theta q_{n 0} \\
\sum_{i=1}^{N} z_{i} x_{i m} \leq x_{m 0} \\
\sum_{i=1}^{N} z_{i}=1 \\
i=1,2, \ldots, N \\
\widehat{F}_{i}^{I}\left(q_{i}, x, q, x \mid V R S\right)=\min _{z, \theta} \theta \\
s . t . \\
\sum_{i=1}^{N} z_{i} q_{i n} \geq q_{n 0} \\
\sum_{i=1}^{N} z_{i} x_{i m} \leq \theta x_{m 0} \\
\sum_{i=1}^{N} z_{i}=1 \\
i=1,2, \ldots, N
\end{gathered}
$$

where $q$ is an $n \times N$ matrix of outputs, $x$ is a $m \times N$ matrix of inputs, $z_{i}$ are the intensity factors used to construct the bestpractice frontier and $\theta$ is the level of efficiency to be estimated. The technical efficiency measures are calculated on a year by year rather than pooled basis to allow for appropriate comparison with TFP efficiency measures.

Recent literature has shown that the mean of efficiency scores estimated from DEA models tend to have substantial biases that may dominate the variance, a problem that Kneip et al. (2015) called 'bias killing the variance'. This implies that the estimated mean technical efficiency score does not necessarily converge to the true mean efficiency score as the sample size of decision-making units under investigation increases (Kneip et al. 2015; Simar and Zelenyuk 2018, 2020; Daraio et al. 2018). Fortunately, Simar and Zelenyuk (2020) and Kneip et al. (2015) have provided a simple method for correcting the bias from the mean of DEA scores estimated from a finite sample to comply with the central limit theory (CLT). We follow Simar and Zelenyuk (2020) to correct for bias in the mean technical efficiency scores from the estimated DEA scores by first estimating the simple sample mean:

$\bar{F}_{n}=n^{-1} \sum_{i-1}^{N} \widehat{F}\left(q_{i}, x_{i}, q, x \mid V R S\right)$

The estimated simple sample mean is used to compute the bias correction as follows:

$$
\widehat{B}_{n, k}=\left(2^{k}-1\right)^{-1}\left(\bar{F}_{n / 2}^{*}-\bar{F}_{n}\right)
$$

where $k$, the rate of convergence of the estimated mean to true mean, is equal to $\frac{2}{x+q}$ under a constant returns to scale technology and $\frac{2^{x+q}}{x+q+1}$ under a variable returns to scale technology. $\bar{F}_{n / 2}^{*}$ is a generalised jacknife of the simple standard mean such that:

$$
\bar{F}_{n / 2}^{*}=\frac{\left(\bar{F}_{n / 2}^{(1)}+\bar{F}_{n / 2}^{(2)}\right)}{2}
$$

In Eq. $14, \bar{F}_{n / 2}^{(1)}$ is a random subset of the sample and $\bar{F}_{n / 2}^{(2)}$ is the analogue based on the balance of the sample. It is noted that any correction of the bias in the mean technical efficiency estimates for both constant and variable returns to scale necessitates re-estimation of the estimates for the mean scale and residual mix efficiencies.

\section{An empirical comparison of efficiency measures}

\subsection{Investigating the determinants of TFP efficiency and orientation restricted technical efficiency}

To compare how sources of heterogeneity at the firm level impact the efficiency measures, the generalised method of 
moments (GMM) is applied. GMM is a method that uses two sets of population moment conditions (i.e., mean and variance) in a manner that minimises the asymptotic variance among the method of moment estimators of the population mean (Wooldridge 2001). GMM is chosen instead of a fixed-effects estimator because of its capacity to address potential endogeneity in models, which can arise where an unobserved factor related to an efficiency estimate (our dependent variable) is also related to an independent variable, resulting in a correlation between that independent variable and the error term. For example, an anticipated case of endogeneity arises from the use of a debt-to-equity ratio as an explanatory variable because productive efficiency may influence a firm's financial performance through its ability to access credit needed for capital investment.

The system GMM model is also preferred because of its ability to deal with the potential serial correlation problem when the lags of efficiency estimates are used as explanatory variables in a dynamic model (Arellano and Bond 1991). The application of the fixed-effects estimator requires the strict assumption of exogeneity. In relaxing this assumption, GMM provides a consistent estimator in the presence of heteroscedasticity, i.e., where the variability of efficiency estimates is unequal across a range of values of a predictor variable over time (Baum et al. 2003).

The System GMM (Blundell and Bond 1998, 2000) estimates a system of simultaneous equations as shown in Eqs. 15 and 16:

$$
\begin{aligned}
& E_{i, t}=\alpha E_{i, t-1}+X_{i, t}^{\prime} \beta+\left(\mu_{i}+v_{i, t}\right) \\
& E_{i, t}-E_{i, t-1}=\gamma\left(E_{i, t-1}-E_{i, t-2}\right)+\left(X_{i, t}^{\prime}-X_{i, t-1}^{\prime}\right) \beta+\left(v_{i, t}-v_{i, t-1}\right),
\end{aligned}
$$

where $\gamma=1+\alpha$ and $E_{i, t}-E_{i, t-1}$ is the difference in the efficiency measures of firm $i$ at time $t$ and $t-1$. The error term in Eq. 15, $\left(\mu_{i}+v_{i, t}\right)$ consists of two identically and independently distributed components, wherein $\mu_{i}$ is the time-invariant unobserved heterogeneity within each production unit and $v_{i, t}$ is the idiosyncratic term. Equation 15 provides an estimator in levels and Eq. 16 provides an estimator based on first differences. Equation 16 alone is referred to as the Difference GMM (Arellano and Bond 1991). The System GMM overcomes the finite sample bias problem in the presence of weak instruments that the Difference GMM is subject to, which is a product of unit root property exhibition by individual time series. The use of the System GMM enables the inclusion of year level dummies in the model to account for year effects on the efficiency estimates. This is not possible in the application of the Difference GMM.

A two-step GMM estimator is chosen as it has greater asymptotic efficiency than a one-step estimator. To overcome the downward bias of the standard errors estimated by the standard efficient two-step GMM estimator, the finite sample corrected variance estimate, as proposed by Windmeijer (2005), is implemented in the estimation of the standard errors. To test the specification of the model, the Arellano-Bond test (Arellano and Bond 1991) for autocorrelation is used to test for serial correlation in the first differenced errors. The Hansen test (Hansen 1982) is used to test for over-identification restrictions to examine the validity of the instruments used in the model.

\subsection{Testing for convergence in efficiency measures}

Given the wide heterogeneity across farms, efficiency measures are expected to vary across and within farms over time. Therefore, it is important to examine how the dispersion of TFP efficiency and orientation restricted technical efficiency measures differ as this has important policy implications. The presence of sigma convergence within periods is examined to investigate whether cross-sectional dispersion of TFP efficiency and technical efficiency measures declines over time. Though several prior studies have estimated sigma convergence of TFP estimates in the context of agriculture inclusive of Suhariyanto and Thirtle (2001), Ball et al. (2004, 2014), Poudel et al. (2011), Mugera et al. (2012) and Baráth and Fertó (2017), there has been limited prior investigation of convergence of either TFP efficiency or technical efficiency at the farm level. To examine sigma convergence, this study follows the approach by Sala-i-Martin (1996), Liu et al. (2011) and Baráth and Fertô (2017) whereby cross-sectional standard deviation of the natural $\log$ of the variable of interest is estimated (in the case of this study, the efficiency measure) and regressed against time:

$\operatorname{var}\left(\ln \left(E_{t}\right)\right)=\omega_{1}+\omega_{2} t+\varepsilon_{t}$

where $\operatorname{var}\left(\ln \left(E_{t}\right)\right)$ is the across-farm variance of the logarithm of the efficiency measure in period $t$ (in the case of this study, the year), $\omega_{1}$ and $\omega_{2}$ are parameters to be estimated and $\varepsilon$ is a zero-mean random error disturbance term. If $\omega_{2}$ (the slope) is negative, this implies that sigma convergence exists. That is, for sigma convergence to hold, the cross-sectional standard deviations of the efficiency measure (itself a cross-sectional measure) must decrease over time. In the context of TFP efficiency and without allowance for technical regress, sigma convergence would imply that there is a reduction of disparities in the overall productive efficiency of farms over the study period. If sigma convergence is observed in technical efficiency estimates, it will imply that the disparities in managerial performance across farms are diminishing over time. This study does not estimate beta convergence as the focus of the study is not on whether or not there were farms that started 
with lower levels of efficiency at the beginning of the sample period yet were able to catch up with those that had higher levels of efficiency. However, it is important to note that sigma convergence is a necessary condition for beta convergence.

\section{Application to Western Australia}

\subsection{Survey region}

The study used a balanced panel of 64 mixed crop-livestock farms in Western Australia's Wheatbelt region over the period 2002-2011. In 2017/2018, the value of Western Australia's grain exports was A $\$ 5$ billion, accounting for approximately $40 \%$ of Australia's grain exports. The Wheatbelt region is in the south-west corner of Western Australia and covers a total area of about 197,300 square kilometres, of which over $60 \%$ is used for agriculture. In the period 2015-2016, the gross value of agricultural production in the region was about $\mathrm{A} \$ 4.6$ billion, which was over $55 \%$ of the total gross value of agricultural production in Western Australia. A survey of more than 550 farms over a 6-year period (Planfarm-Bankwest 2013) showed the primary driver of revenue variance between the performance of the top $25 \%$ and the bottom $25 \%$ was production yields rather than received prices. The difference in average prices received between these groups was less than $3 \%$.

\subsection{Production data and variable selection}

The data were obtained from a consulting business that services the study region. Only farms that provided data for all ten years were included; it is noted that this may introduce some potential bias through the failure to capture the entry and exit of farm businesses in this period (see Foster et al. 2008). The farm sizes ranged from 1150 to 12,730 hectares with an average size of 3990 hectares and an average revenue of $\mathrm{A} \$ 1.30$ million. The survey group may be considered representative of farms in Western Australia's Wheatbelt: the Planfarm-Bankwest Benchmarks (2011) for 2010/2011, the largest comprehensive survey of financial and production performance measures of over 500 farms in Western Australia, shows average farm size in 2010/2011 at 4185 hectares and average revenue at $\mathrm{A} \$ 1.03$ million.

The farm data collected contain information about input and output quantities, farm size, and enterprise characteristics. It also includes information on financial performance, as well as farmer characteristics such as age and education. Aggregate crop and livestock output variables, input variables and other variables that describe farm characteristics were constructed from the data set. In selection of the production inputs and outputs, it is important to consider dimensionality. Recent simulation studies have shown that in the context of limited sample sizes, a greater number of dimensions (i.e., inputs and outputs) slows the rate of convergence of estimates towards their 'true' values, which may adversely impact the inference drawn from analysis of efficiency estimates (Kneip et al. 2015, 2016; Daraio et al. 2018; Simar and Zelenyuk 2018, 2020; Zelenyuk 2020).

The present study achieves a reasonable level of discrimination as set forth by Dyson et al. (2001), since the number of units (in our case 64) is more than twice the sum of the inputs and outputs (7). Following recent studies in agricultural economics (Mugera et al. 2016; Baráth and Fertö 2017; Dakpo et al. 2018; Ang 2019), our study only includes discretionary inputs in the production model. Discretionary inputs are inputs such as seeds, fertiliser, and fuel that farm businesses can directly control and adjust. The present study was limited by the absence of specific rainfall, temperature, or soil condition variables amongst the farm level data used. Future studies and applications of TFP efficiency may benefit from the inclusion of environmental variables into their production models per the recent works of Liang et al. (2017), Njuki et al. (2018), Chambers and Pieralli (2020) and Plastina et al. (2021). Despite not being able to adjust these factors of production directly, it is expected that farm businesses would adjust their use of discretionary inputs in anticipation and reflection of their production environments. For example, a rational farm manager may tactically reduce the rate of application of fertiliser or herbicides in anticipation of drought. Table 1 provides a summary of the variables used in the estimation of the Färe-Primont output and input aggregator functions.

Two output variables were used for the construction of the Färe-Primont output aggregate. Crop output $\left(\mathrm{q}_{l}\right)$ is the total revenue for all crops produced on an individual farm per year measured in Australian dollars and normalised by the crop price index to the base year of 2002 (ABARES 2012). Livestock output $\left(q_{2}\right)$ is a measure of the total revenue in Australian dollars from livestock activities (livestock sales and wool) normalised by the Australian Bureau of Agricultural and Resource Economics and Sciences (ABARES) index of livestock prices with 2002 as the base year (ABARES 2012).

Five discretionary input variables were used in the estimation of the Färe-Primont input aggregate. Labour $\left(x_{1}\right)$ is calculated as the aggregate number of weeks of both permanent and casual labour used per year. Expenditure on crop inputs $\left(x_{2}\right)$, operational inputs $\left(x_{3}\right)$ and livestock production inputs $\left(x_{4}\right)$ were all normalised with 2002 as the base year by their respective component price indexes as provided by ABARES (2012). The crop input is an aggregate measure of expenditure on fertiliser, chemicals, and seeds. The operational cost is an aggregate measure of expenditure on contract services, repair and maintenance, 
Table 1 Summary statistics of production data $(N=64)$

\begin{tabular}{llllll}
\hline Measure & Units & Mean & SD & Minimum & Maximum \\
\hline Crop output $\left(q_{1}\right)$ & A $\$$ & $1,092,580$ & 854,861 & 0 & $7,318,886$ \\
Livestock output $\left(q_{2}\right)$ & A $\$$ & 114,702 & 126,025 & 0 & $1,318,364$ \\
Labour $\left(x_{1}\right)$ & Person weeks & 122 & 44 & 52 & 305 \\
Crop inputs $\left(x_{2}\right)$ & A $\$$ & 329,053 & 220,483 & 23,206 & $1,758,859$ \\
Operational costs $\left(x_{3}\right)$ & A $\$$ & 150,153 & 104,423 & 41,612 & 969,225 \\
Livestock production inputs $\left(x_{4}\right)$ & A $\$$ & 21,144 & 40,996 & 0 & 545,667 \\
Land under production $\left(x_{5}\right)$ & Hectares & 3990 & 2086 & 1150 & 12,730 \\
\hline
\end{tabular}

and fuel. The livestock production input is an aggregate measure of expenditure on livestock purchased and livestock expenses such as feed and treatments. The final variable is land under both crop and livestock $\left(x_{5}\right)$ measured in hectares.

\subsection{Potential determinants of efficiency}

Table 2 provides a summary of the key variables used to investigate the determinants of the estimated efficiency measures $^{3}$.

Diversification is considered to examine whether choices in the production mix influence the efficiency of farms in the survey area. Diversification is represented by the Berry index (Berry 1971) computed as follows:

$d^{B}=1-\sum_{i=1}^{N} s_{i}^{2}$

where $s_{i}$ is the share of revenue generated by the $i$ th enterprise and $N$ is the number of enterprise types. There are two main enterprise types for the farms in this study, crop production and/or livestock production. The Berry index ranges from 0 and 1 , where a higher score indicates more degree of diversification. Production diversification reflects a farm's risk management strategy consistent with standard portfolio theory (Markowitz 1952). In a prior study of Australian mixed enterprise farming, Sheng et al. (2016) identify a negative and significant association between TFP and production diversification.

The ratio of off-farm income to aggregate revenue is included to examine whether reduced reliance on farm income, as a component of total income, influences the efficiency estimates. A higher ratio of off-farm income to aggregate receipts is expected to have a negative effect on farm-level efficiency; this is because farm operators must direct more time and knowledge away from farming

\footnotetext{
${ }^{3}$ The variables selected are based on those provided by the farm business consultants. Other metrics such as soil quality may also have been considered, but data were not available.
}

activities to generate off-farm income (Mishra and Sandretto 2002; Yee et al. 2004; Sabasi et al. 2019).

The ratio of debt-to-equity (i.e., the capital structure) is included in determining the impact of greater debt use on farm-level efficiency. It is expected that increased access to capital will improve access to technology and hence relative performance (Zhengfei and Oude Lansink 2006). The ratio of debt-to-equity is a prospective source of endogeneity in the System GMM model to be estimated since farm productive performance may affect farm business creditworthiness and therefore its capital structure. The impact of capital investment (money spent on land, plant, and equipment) on the various efficiency measures is considered by the inclusion of the ratio of capital expenditure to aggregate payments of the farm businesses in both the present period and its lag. Aggregate payment includes capital, operational and financial expenses of a farm business in a period. It is included to examine whether higher relative capital expenditure improves efficiency. Investment in improved capital equipment and the plant is hypothesised to improve efficiency.

The ratio of contract service expenditure to total operational costs is included to examine how the use of contract services influences farm level efficiency. The study of Key and McBride (2003) on United States hog production found that contract services increased partial factor productivity, which was attributed to enhanced knowledge transfer and development across operations. The effect of farm enterprise size on efficiency is considered through the inclusion of scaled total farm revenue ${ }^{4}$. It is expected that farm size will influence scale efficiency as a component of relative efficiency. The use of gross farm revenue for the classification of farm size is consistent with the method used by Mugera and Langemeier (2011) as well as Briggeman (2011).

Primary operator age is included to examine whether management experience is significant to efficiency; older farm operators are hypothesised to have greater experience and use resources more efficiently. A dummy for primary operator education is included to examine whether human

\footnotetext{
${ }^{4}$ Total farm revenue is divided by $1,000,000$
} 
Table 2 Summary of farm-level heterogeneity variables

\begin{tabular}{|c|c|c|c|c|c|}
\hline Measure & $N$ & Mean & SD & Minimum & Maximum \\
\hline Diversification & 640 & 0.1787 & 0.1452 & 0.0000 & 0.5000 \\
\hline Off-farm income/aggregate receipts & 640 & 0.0561 & 0.0938 & -0.1641 & 0.8564 \\
\hline Debt/equity & 640 & 0.2674 & 0.2129 & 0.0034 & 1.5560 \\
\hline Capital expenditure/aggregate payments & 640 & 0.1309 & 0.1291 & -0.0032 & 0.7793 \\
\hline Contract expenditure/operational costs & 640 & 0.0336 & 0.0359 & 0.0000 & 0.3059 \\
\hline Enterprise size & 640 & 1.2456 & 0.8915 & 0.0509 & 7.6120 \\
\hline Primary operator age & 640 & 44.8594 & 10.8545 & 18 & 69 \\
\hline Rainfall zone (dummy) & & $\%$ & & & \\
\hline Low & 330 & 51.5625 & & & \\
\hline Medium & 310 & 48.4375 & & & \\
\hline \multicolumn{6}{|l|}{ Education (dummy) } \\
\hline Tertiary—non-university & 500 & 78.1250 & & & \\
\hline Tertiary_university & 140 & 21.8750 & & & \\
\hline
\end{tabular}

capital, as measured by university-level education, has an impact on efficiency estimates. Reimers and Kaslan (2012) used a dummy variable with farmers categorised as either university or not university-educated to investigate the effect of schooling on agricultural productivity in developing and emerging countries. A dummy for rainfall zone is included to examine whether farm businesses in the medium rainfall zone are less efficient than those in the low rainfall zone. It is important to note that a rainfall zone captures more than average precipitation levels: farm businesses in the low rainfall zones of the study region are located further east (inland) than medium rainfall regions positioning them further from major ports and population centres, with typically sandier soil profiles, higher temperatures, and lower humidity levels. In a study of farms in Western Australia's Wheatbelt between 1998 and 2008, Islam et al. (2014) found that farm businesses in the medium rainfall zone experienced higher TFP efficiency growth than farm businesses in the low rainfall zone.

\section{Efficiency estimates and trends}

This section reports selected estimates of TFP efficiency and its components. All the estimates were obtained using the standard version of DPIN 3.0 software, Stata 16.0 and several packages in R including stargazer (Hlavac 2018), texreg (Leifield 2013), dplyr (Wickham et al. 2021), and $n p$ (Hayfield and Racine 2008).

Figure 2 shows the average annual estimates of TFP, TFP efficiency and the highest observable TFP that could be produced given the available technology in the referenced year. Notable from the figure is that TFP efficiency seems to have been the main driver of TFP until 2005 when increases in the maximum observable TFP dominated TFP efficiency as the primary driver of farm level TFP in the survey region. Total factor productivity estimates generally rose over the

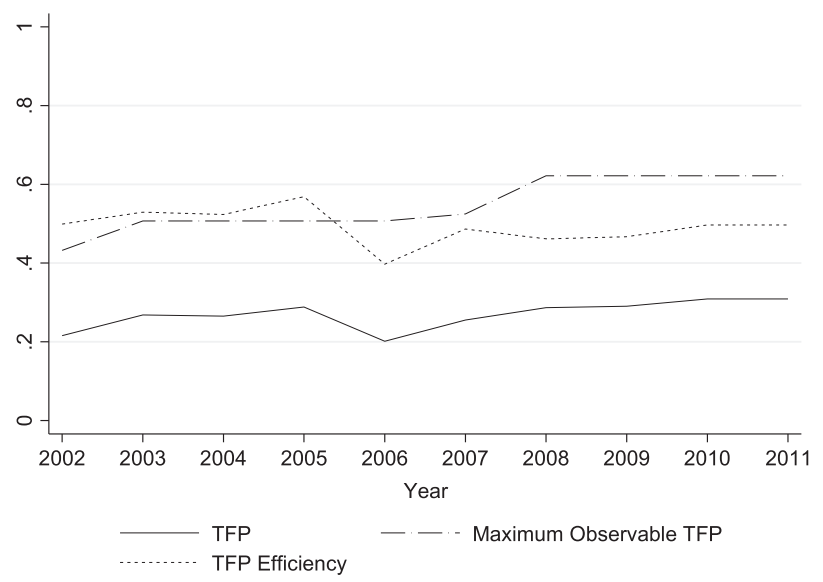

Fig. 2 Mean TFP, maximum TFP observable, TFP efficiency estimates (2002-2011)

study period, except for 2006, a period of drought in the survey region, where the lowest average estimate of 0.2014 was observed. The average TFP efficiency ranged between its lowest value of 0.3973 in 2006 and the highest value of 0.5686 in 2005. Figure 2 suggests that improvements in TFP over the survey period were largely driven by increases in the maximum observable TFP (i.e., upward shifts in the technological frontier), as opposed to an improvement in TFP efficiency. Figure 2 shows that average TFP does not vary much across the years and are driven by both maximum observable TFP and TFP efficiency. A table of the averages for TFP, TFP efficiency and technology is reported in Appendix 1.

Figure 3 shows box plots for TFP efficiency and both output-oriented technical efficiency (OTE) and inputoriented technical efficiency (ITE) scores by year. The top and bottom parts of the boxes indicate the 75th and 25th percentiles, while the line in the middle of the box indicates the median efficiency measure across the study period. The distribution of the measures of TFP efficiency is different 
TFP Efficiency

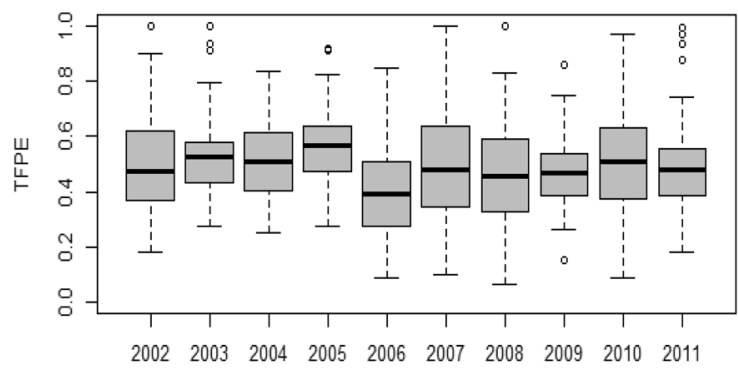

Year

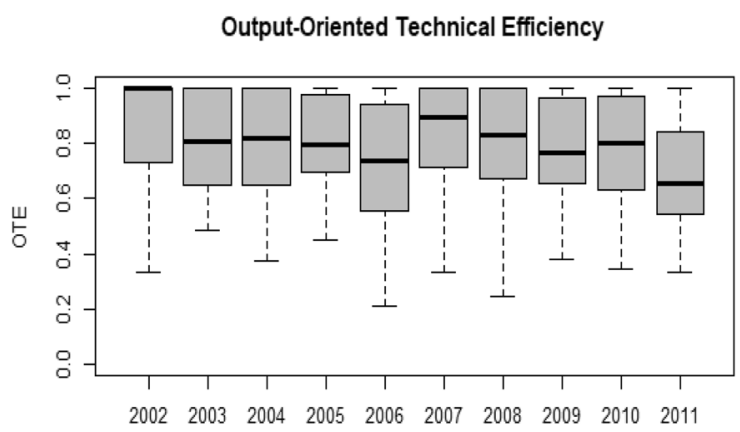

Input-Oriented Technical Efficiency

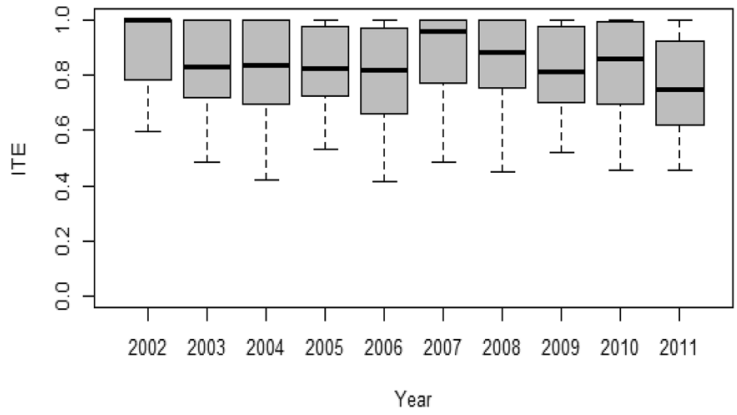

Year

Fig. 3 TFP efficiency, output-oriented technical efficiency, and input-oriented technical efficiency box plots (2002-2011)

from that of the oriented technical efficiency measures. TFP efficiency has a maximum observed score of 1 in 2002 , 2003, 2007, 2008, and 2011. This implies that the TFP efficiency estimates may be interpreted as the competitiveness of a farm business relative to the most productive firm from the sample in these periods. In periods where no TFP efficiency score of 1 is observed, it suggests that no firm was able to maximise its productive output given the technology available. The lowest minimum TFP efficiency score was observed in 2008, when the minimum estimate was 0.0642 , while the highest minimum score was 0.2756 in 2003. In contrast to TFP efficiency, the median ITE and OTE scores were very high. In 2002, the median estimates for both ITE and OTE equalled to $1^{5}$, meaning that the median estimate was on the mix restricted production frontier. In 2003, 2004, 2007, and 2008, the top quartile of firms within the sample had OTE and/or ITE estimates of 1 . By contrast in 2002, the median TFP efficiency was only 0.4726 . This means that by relaxing the assumption of mix restriction, the median observation was only $47.26 \%$ as productive as the best performing firm within the sample in 2002.

Figure 4 presents pooled scatter plots of TFP efficiency against ITE and OTE. The results show a weak positive correlation exists between TFP efficiency and technical efficiency measures. In many cases where a farm achieves

\footnotetext{
$\overline{5}$ The bias correction factors estimated pursuant to Kneip et al. (2015) all may be approximated to zero.
}

technical efficiency and sits on the mix-restricted frontier, its overall production efficiency is low. To support the results of the scatter plot, Spearman rank correlations are estimated between TFP efficiency, ITE and OTE estimates. The rank correlation estimates are shown in Fig. 5.

The highest rank correlation between TFP efficiency and ITE is 0.6711 , while the highest rank correlation between TFP efficiency and OTE is 0.7346; both estimates were in 2004 . The lowest rank correlation between TFP efficiency and ITE is 0.2200 in 2007, while the highest rank correlation between TFP efficiency and OTE is 0.4386 in 2002. A strong rank correlation exists between ITE and OTE estimates in all years, ranging from 0.8332 in 2007 to 0.9870 in 2002 . A table of the rank correlations is provided in Appendix 2.

To further contrast TFP efficiency against ITE and OTE as benchmarks of productive performance, we investigate the variability that exists within periods for each of the measures. Figure 6 provides a graphical representation of the coefficients of variation (CV) for TFP efficiency, OTE, and ITE. The CV estimates over the survey period indicate TFP efficiency estimates vary more than ITE and OTE estimates.

To examine the dispersion of TFP efficiency, ITE and OTE estimates over time, sigma convergence was tested per the method of Sala-i-Martin (1996). The results of the regression analysis are reported in Table 3. The coefficient for the time variable is positive and significant at $1 \%$ level in the TFP efficiency, ITE and OTE models. This result suggests that all measures diverged over the study period. The 
Fig. 4 Pooled scatter plot comparisons of TFP efficiency and orientation-restricted technical efficiency measures

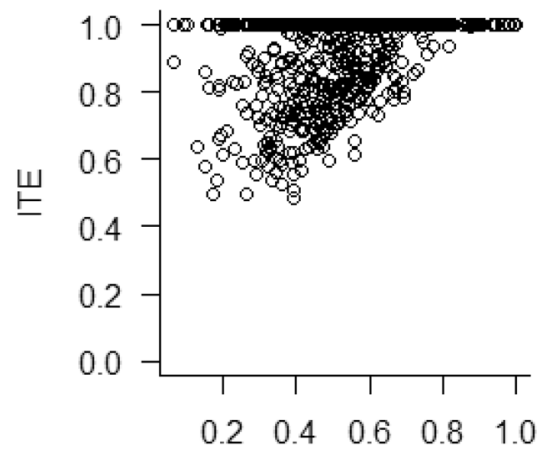

TFPE

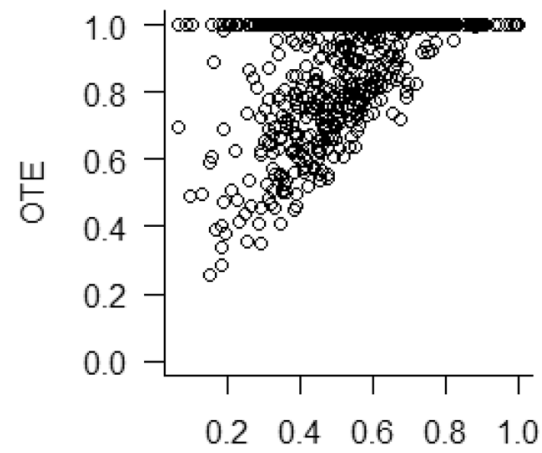

TFPE

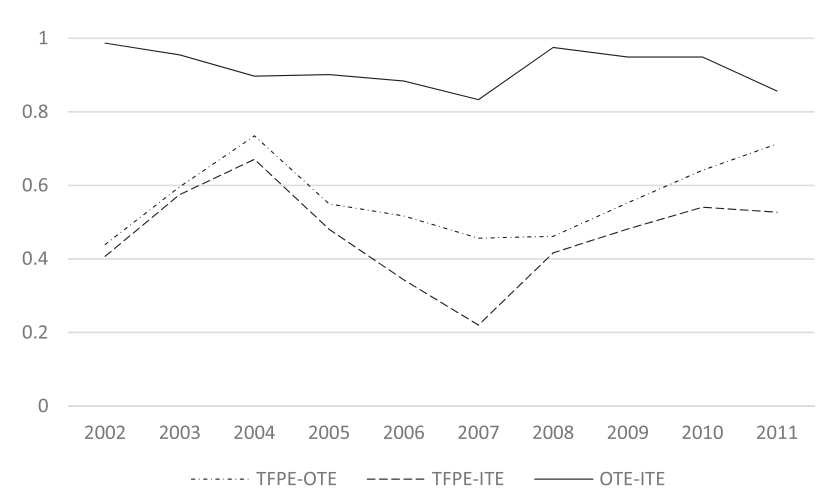

Fig. 5 Spearman's rho between TFP efficiency, output-oriented technical efficiency, and input-oriented technical efficiency (2002-2011)

coefficient of the time variable for the TFP efficiency estimate was 0.0074 , as opposed to 0.0030 for OTE and 0.0018 for ITE. This indicates TFP efficiency estimates diverged more widely than ITE and OTE over the study period.

To examine the impact of the different component of efficiency measures on TFP efficiency, Fig. 7 presents the nonparametric kernel density estimate plots ${ }^{6}$ of TFP efficiency and its component measures using the pooled results for the study period. Summary statistics for TFP efficiency and these component measures are reported in Appendix 3. Figure 7 shows that ITE and OTE estimates, as well as output scale efficiency (OSE) and input scale efficiency (ISE) estimates, are all strongly concentrated around 1. By contrast to measures of technical and scale efficiency, the distribution of residual mix efficiency (RME) estimates more closely reflect the distribution of TFP efficiency estimates.

We extend the analysis in Fig. 7 by attempting to illustrate the contribution of each of the three multiplicatively complete efficiency components of TFP efficiency to its distribution; we do this by sequentially introducing each component as in Eqs. $6 \mathrm{a}$ and $6 \mathrm{~b}$. The output-oriented introducing effects and input-oriented introducing effects

\footnotetext{
${ }^{6}$ The bandwidth of the kernels estimated is optimised through application of the Mean Integrated Squared Error criterion.
}

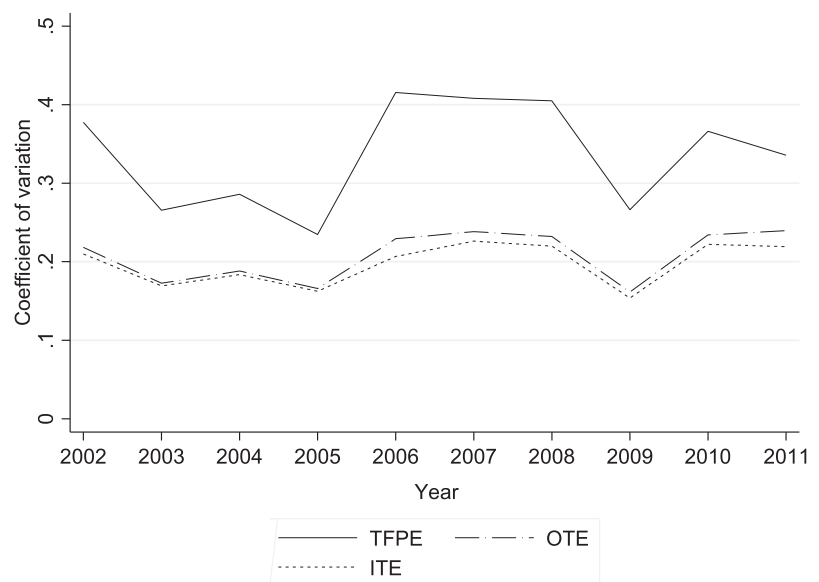

Fig. 6 TFP efficiency, output-oriented technical efficiency, and inputoriented technical efficiency coefficients of variation (2002-2011)

are shown in Figs. 8 and 9, respectively. In both figures, the top left panel shows the distribution of TFP efficiency while the top right panel shows the distributions of TFP efficiency and either OTE or ITE. The lower left panel in Fig. 8 shows the distributions of TFP efficiency, OTE and the measure multiplying OTE and OSE (OTSE). The lower left panel in Fig. 9 shows the distributions of TFP efficiency, ITE and the measure multiplying ITE and ISE (ITSE). The distributions of the multiplicative measures OTSE and ITSE are strongly skewed relative to the more normal distribution of TFP efficiency. The lower right panels in Figs. 8 and 9 show the distribution of the measure multiplying technical efficiency by both scale efficiency and residual mix efficiency (OTSE $\times$ RME and ITSE $\times$ RME). The multiplication of the OTSE and ITSE measures by RME results in the combined distributions being shifted to overlay the distribution of TFP efficiency. Therefore, the primary driver of the distribution of TFP efficiency and hence relative productive performance appears to be residual mix efficiency, as opposed to orientation-restricted technical efficiency or scale efficiency. The implication of this result is that the relative productive competitiveness of farm 
Table 3 Variance convergence analysis of TFP efficiency (TFPE), output-oriented technical efficiency (OTE), and input-oriented technical efficiency (ITE)

\begin{tabular}{|c|c|c|c|c|c|}
\hline & Parameter & Coefficient & Standard error & $95 \%$ Conf & interval \\
\hline \multirow[t]{2}{*}{ TFPE } & Intercept & $-14.6521 * * *$ & 1.9881 & -18.5487 & -10.7555 \\
\hline & Slope & $0.0074 * * *$ & 0.0010 & 0.0054 & 0.0093 \\
\hline \multirow[t]{2}{*}{ OTE } & Intercept & $-5.8437 * * *$ & 0.7655 & -7.3441 & -4.3433 \\
\hline & Slope & $0.0030 * * *$ & 0.0004 & 0.0022 & 0.0037 \\
\hline \multirow[t]{2}{*}{ ITE } & Intercept & $-3.5281 * * *$ & 0.2184 & -3.9563 & -3.1002 \\
\hline & Slope & $0.0018 * * *$ & 0.0001 & 0.0016 & 0.0020 \\
\hline
\end{tabular}

***Significant at a $1 \%$ level
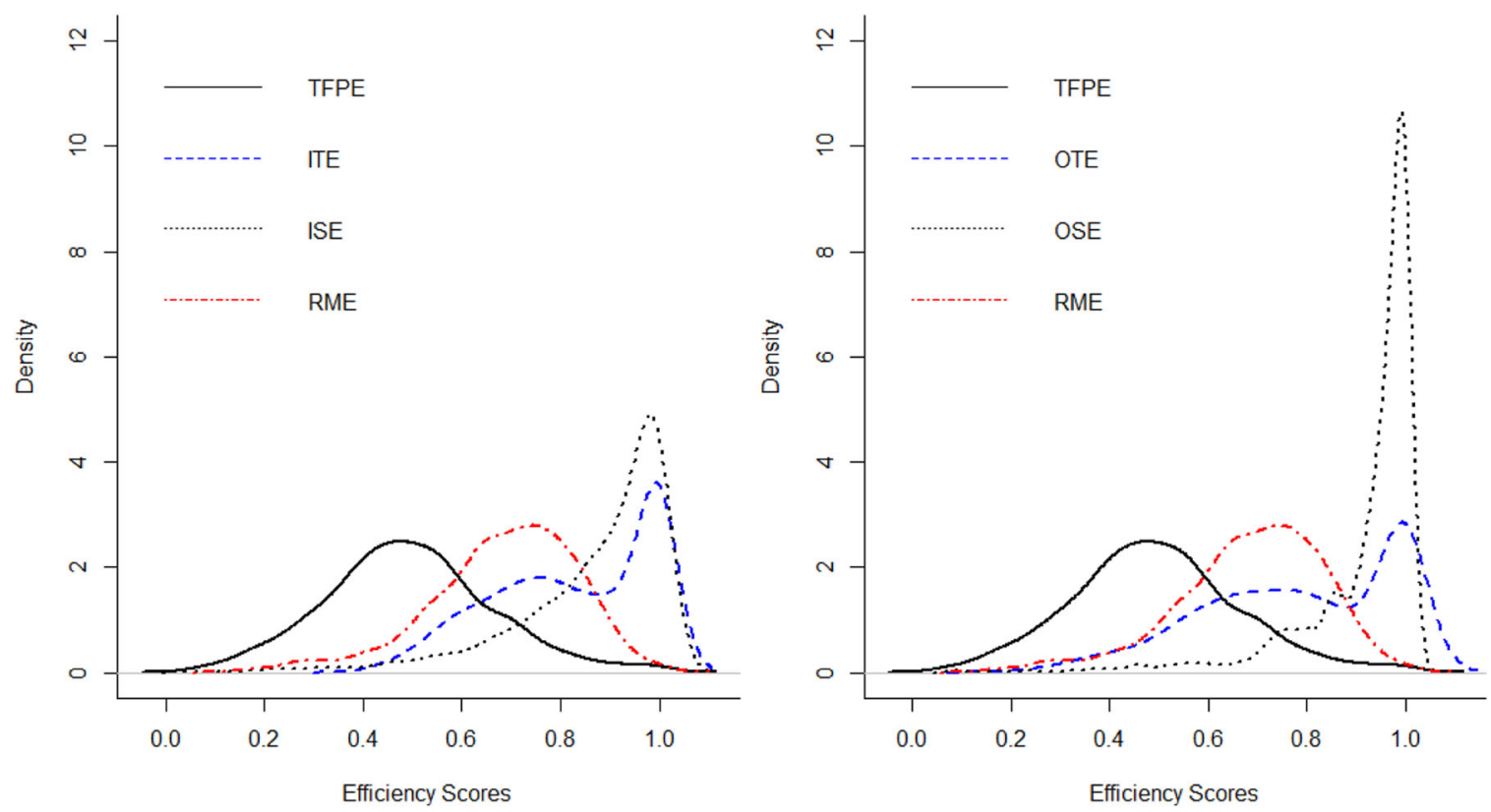

Fig. 7 Density distributions-TFP efficiency and component efficiency measures

businesses in the study area was influenced more by the mix of production inputs and outputs chosen by farm managers than the effectiveness with which these inputs were used.

To further investigate the impact of the counterfactual distribution components on the distribution of TFP efficiency estimates, we follow Kumar and Russell (2002) in testing for equality of the distribution generated by the density function of TFP efficiency against the distributions generated by the density functions of the counterfactual components. The study adopts the method of $\mathrm{Li}$ et al. (2009) to generate kernel-based tests for equality of the density functions. This method uses data-driven bandwith selection methods and smooths continuous and discrete variables through least-squares cross-validation. In our application, bootstrapping is used to obtain a limiting (asymptotic) null distribution. The results of the hypothesis test in Table 4 show that the null hypothesis that the distributions of TFP efficiency and those of OTE, ITE, OTE $\times$ OSE, and ITE $\times$ ISE are identical can be rejected at a $1 \%$ level. As expected from their construction, the null
Table $4 \mathrm{Li}$ equality of distribution tests ${ }^{7}$

\begin{tabular}{lc}
\hline Null hypothesis $\left(\mathrm{H}_{0}\right)$ & Li-test statistic \\
\hline$f(T F P E)=g(O T E)$ & $139.75^{* * *}$ \\
$f(T F P E)=g(I T E)$ & $139.87^{* * *}$ \\
$f(T F P E)=g(O T E \times O S E)$ & $85.815^{* * *}$ \\
$f(T F P E)=g(I T E \times I S E)$ & $85.816^{* * *}$ \\
$f(T F P E)=g(O T E \times O S E \times R M E)$ & -1.6557 \\
$f(T F P E)=g(I T E \times I S E \times R M E)$ & -1.6569
\end{tabular}

*** $\mathrm{H}_{0}$ rejected at a $1 \%$ level

hypothesis that the distributions of TFP efficiency and those of $\mathrm{OTE} \times \mathrm{OSE} \times \mathrm{RME}$ and ITE $\times$ ISE $\times$ RME are identical cannot be rejected at $10 \%$ level.

\footnotetext{
$\overline{7}$ The null hypothesis is that the two distributions are equal. Gaussian kernel estimation is used with the bandwidth selected using Silverman's (1986) rule, and with 2000 bootstrap iterations
} 

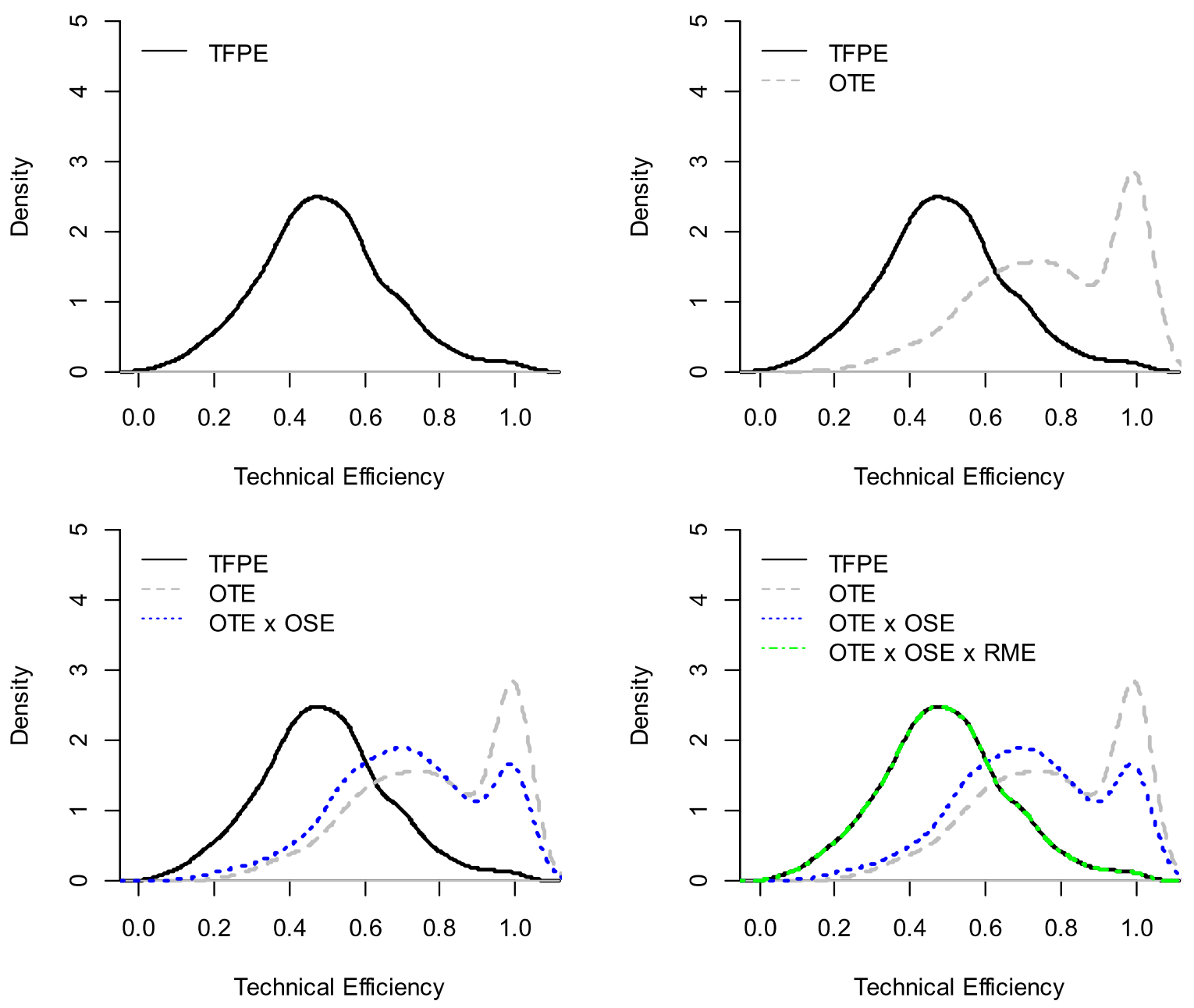

Fig. 8 Counterfactual distributions of TFP efficiency-multiplicative output-oriented component measures

\section{Efficiency determinant results and comparison}

The second stage of the analysis compares sources of observable heterogeneity at the farm level that affect TFP efficiency, ITE and OTE. The System GMM regression results are reported in Table 5. For robustness, ordinary least squares ('OLS') and Tobit regression results are reported in Appendix $4^{8}$.

The regression for each model uses 55 instruments, satisfying the requirement that the number of instruments is

\footnotetext{
$\overline{8}$ Banker et al. (2019) have demonstrated through extensive simulations that the simple two-stage DEA + OLS model outperforms all the other two-stage approaches when the contextual variables influence firm performance. However, unlike the System GMM models estimated in this section, DEA + OLS models ignore the potential endogeneity and reverse causality problem arising from efficiency estimates potentially influencing some of the contextual variables. Though instrumental variables may be used to overcome this problem, it is difficult to find suitable instruments that influence the contextual variables and not efficiency measure within our sample data.
}

less than the number of observations, 64. The Arellano-Bond test indicated no second-order autocorrelation in the first differenced errors of all three equations. This suggests that the models are correctly specified in their use of instruments from the $t-2$ and prior periods. The Hansen test results show that the over-identification restrictions are valid since the null hypothesis that the instruments used are valid instruments (uncorrelated with the error term) and that the excluded instruments are correctly omitted from the estimated equations cannot be rejected for each equation at the $5 \%$ level.

The regression results demonstrate that different determinants influence TFP efficiency and technical efficiency measures ${ }^{9}$. The only common determinant that is significant and positive to all measures, considered at a level of $10 \%$ or

\footnotetext{
${ }^{9}$ The results of the ordinary least squares regression reported in Appendix 4 show the same farm characteristics as significant for each performance measure, confirming the findings of the System GMM regression provided in Table 4.
} 


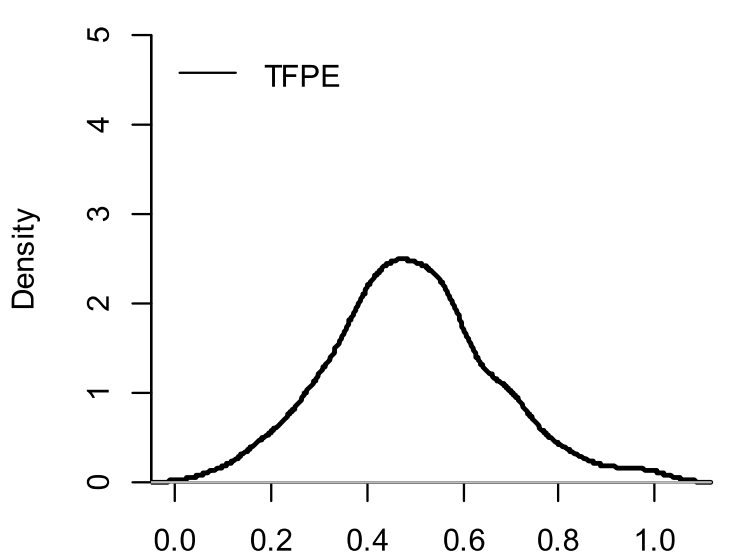

Technical Efficiency

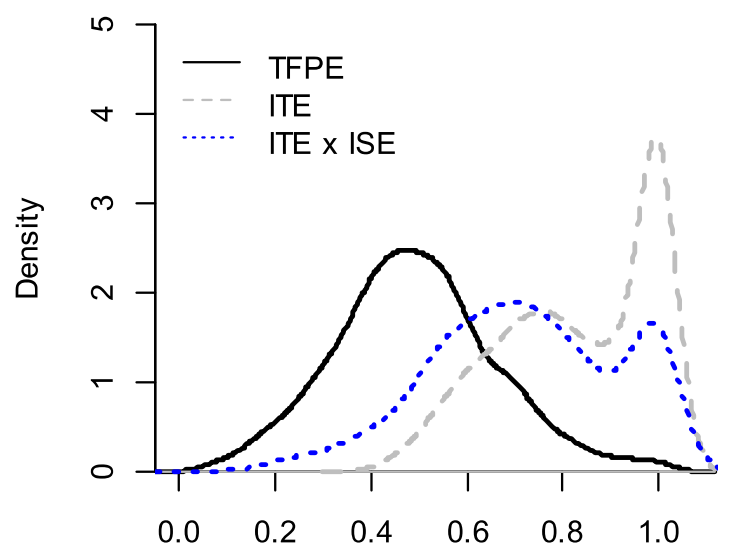

Technical Efficiency

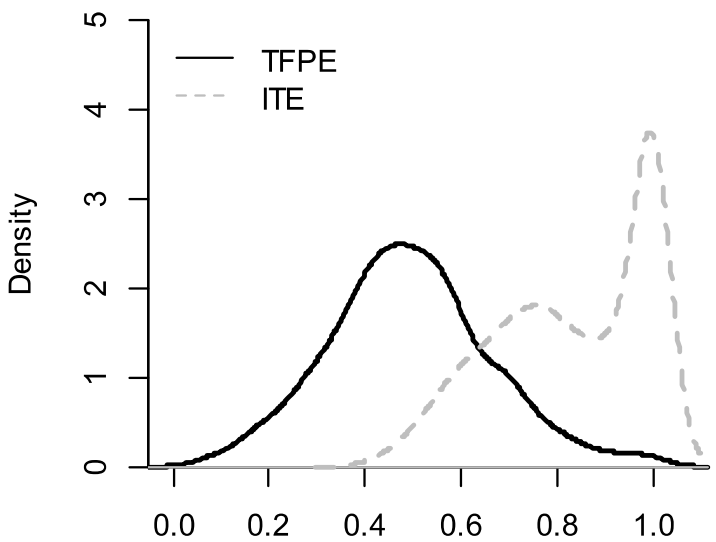

Technical Efficiency

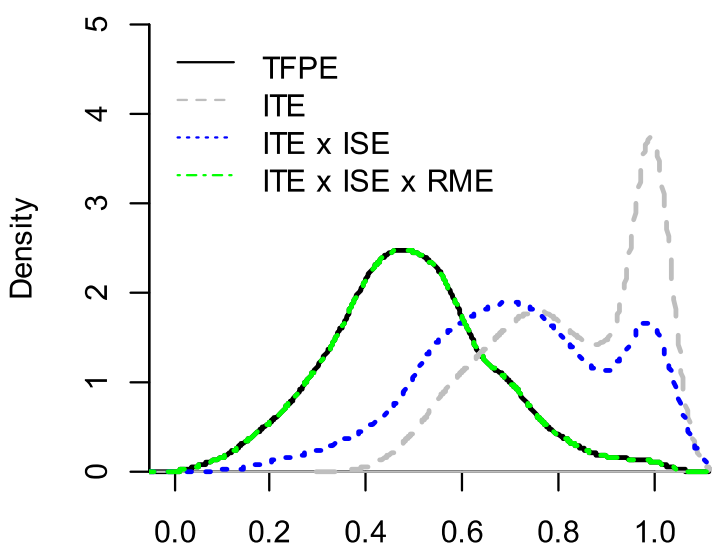

Technical Efficiency

Fig. 9 Counterfactual distributions of TFP efficiency-multiplicative input-oriented component measures

greater, is farm enterprise size, where larger farms perform better. Despite the shared significance, the magnitude of the impact of farm enterprise size on the performance measures varies substantially: the effect of farm enterprise size is greater in the TFP efficiency model $(0.1567)$ compared to the OTE model (0.1227) and the ITE model (0.0709). Both production diversification and the farm business debt-toequity ratio are positively and significantly associated with OTE; production diversification is also positively associated with ITE at a significance level of $1 \%$.

The positive association of enterprise production diversification and technical efficiency may be explained by farm businesses being better able to adapt to variable environmental and market conditions, for instance, through improved land and soil management practices arising from pasture and crop rotation. Several prior studies globally have found that diversification by crop producers leads to technical efficiency gains; those include Rahman (2009) who analysed rice and wheat producers in Bangladesh, Ogundari (2013) who examined mixed cropping enterprises in Southwestern Nigeria, and Ho et al. (2017) who studied coffee farmers in the Central Highlands region of Vietnam.

The positive impact of a higher debt-to-equity ratio on technical efficiency may be explained by the free cash flow theory (Jensen and Meckling 1976). The theory postulates that businesses with greater cash on hand will make more risky investments and apply less effort in the use of their resources; conversely, as a firm's level of debt increases, management will be more prudent and efficient in their resource use. By contrast, farm businesses that have higher costs associated with debt will be motivated to use their available resources more efficiently (Mugera and Nyambane 2014).

By contrast, the reliance of farm businesses on off-farm income is shown to be significant and negatively associated with TFP efficiency. A $10 \%$ rise in the ratio of off-farm income to total income leads to a $1.738 \%$ decline in TFP efficiency. This finding may imply that farm owners that earn a larger proportion of their total income away from their farming operation may be less concerned about optimising the productivity of their farm operations relative to 
Table 5 System GMM estimates of the determinants of TFP efficiency, output-oriented technical efficiency (OTE), and input-oriented technical efficiency (ITE)

\begin{tabular}{|c|c|c|c|c|c|c|}
\hline & \multicolumn{2}{|c|}{ TFP efficiency } & \multicolumn{2}{|l|}{ OTE } & \multicolumn{2}{|l|}{ ITE } \\
\hline & Coef & RSE & Coef & RSE & Coef & RSE \\
\hline$Y-\operatorname{Lag}_{t-1}$ & -0.0463 & 0.0422 & 0.0369 & 0.0550 & 0.1140 & 0.0720 \\
\hline Diversification & -0.0082 & 0.0870 & $0.3485^{* *}$ & 0.1353 & $0.2876 * * *$ & 0.0948 \\
\hline Off-farm income & $-0.1738 * * *$ & 0.0446 & -0.0114 & 0.0884 & -0.0214 & 0.0886 \\
\hline Debt/equity & 0.0062 & 0.0547 & $0.1301 * *$ & 0.0560 & 0.0919 & 0.0558 \\
\hline Cap ex & -0.0311 & 0.0457 & -0.0111 & 0.0727 & 0.0091 & 0.0613 \\
\hline Contractor use & 0.2979 & 0.2684 & 0.0835 & 0.4128 & -0.0514 & 0.4727 \\
\hline Operator age & -0.0005 & 0.0009 & 0.0001 & 0.0014 & -0.0007 & 0.0012 \\
\hline Enterprise size & $0.1567 * * *$ & 0.0330 & $0.1225 * * *$ & 0.0408 & $0.0709 * * *$ & 0.0261 \\
\hline \multicolumn{7}{|l|}{ Rainfall zone (medium) } \\
\hline Low & $-0.0811 * * *$ & 0.0310 & -0.0427 & 0.0370 & -0.0205 & 0.0376 \\
\hline \multicolumn{7}{|l|}{ Education (below) } \\
\hline University & -0.0429 & 0.0442 & -0.0089 & 0.0539 & 0.0011 & 0.0361 \\
\hline Constant & $0.4316^{* * *}$ & 0.0608 & $0.5798 * * *$ & 0.0909 & $0.6179 * * *$ & 0.0881 \\
\hline \multicolumn{7}{|l|}{ Year } \\
\hline 2004 & -0.0062 & 0.0156 & -0.0145 & 0.271 & -0.0068 & 0.0294 \\
\hline 2005 & $0.0410 * * *$ & 0.0135 & -0.0069 & 0.0209 & -0.0033 & 0.0171 \\
\hline 2006 & $-0.0570 * * *$ & 0.0216 & $-0.0676 * *$ & 0.0299 & -0.0128 & 0.0301 \\
\hline 2007 & -0.0274 & 0.0229 & -0.0036 & 0.0329 & 0.0399 & 0.0262 \\
\hline 2008 & $-0.0897 * * *$ & 0.0241 & -0.0315 & 0.0329 & 0.0082 & 0.0304 \\
\hline 2009 & $-0.0905^{* * *}$ & 0.0160 & -0.0640 & 0.0329 & -0.0272 & 0.0261 \\
\hline 2010 & $-0.0630 * * *$ & 0.0240 & $-0.1080 * * *$ & 0.0390 & -0.0397 & 0.0351 \\
\hline 2011 & $-0.0887 * * *$ & 0.0233 & $-0.1962 * * *$ & 0.0415 & $-0.1118 * * *$ & 0.0298 \\
\hline Number of instruments & & 55 & & 55 & & 55 \\
\hline Number of groups & & 64 & & 64 & & 64 \\
\hline Arellano-Bond & $z$ & $\operatorname{Pr}>z$ & $z$ & $\operatorname{Pr}>z$ & $z$ & $\operatorname{Pr}>z$ \\
\hline First-order test & -3.78 & 0.000 & -4.81 & 0.000 & 4.16 & 0.000 \\
\hline Second-order test & 0.62 & 0.534 & 0.39 & 0.697 & 1.07 & 0.283 \\
\hline Over-identification test & $\chi^{2}(34)$ & $\operatorname{Pr}>\chi^{2}$ & $\chi^{2}(34)$ & $\operatorname{Pr}>\chi^{2}$ & $\chi^{2}(34)$ & $\operatorname{Pr}>\chi^{2}$ \\
\hline Hansen test & 47.43 & 0.063 & 39.94 & 0.223 & 40.80 & 0.196 \\
\hline
\end{tabular}

RSE robust standard error

***Significant at a $1 \%$ level; **Significant at a $5 \%$ level those farm owners who solely rely on farm income. The incidence of lower TFP efficiency, where the proportion of income received from off-farm activities is greater, may also reflect the trade-off in time allocated to farm and non-farm commercial activities. Location in low rainfall regions relative to medium rainfall regions is shown to a negative association with TFP efficiency. This finding is significant at a $1 \%$ level. This result may be explained by farm managers being more conservative in their selection and use of inputs because of potentially greater downside yield risk in low rainfall areas.

The impact of the year level dummies in the estimated models shows that year level effects appear to have a limited impact on input-oriented technical efficiency estimates with only 2011 being observed as negatively affecting input-oriented technical efficiency relative to a 2003 base.
Year fixed-effects are shown in several instances to have a negative impact on output-oriented technical efficiency estimates with 2010 and 2011 shown to be significant at a $1 \%$ level, 2006 significant at a 5\% level, and 2009 at a $10 \%$ level. Relative to 2003 as a base year, 2005 is shown to influence TFP efficiency estimates positively at a $1 \%$ level, whilst 2006, 2008, 2009, 2010 and 2011 are shown to negatively influence TFP efficiency at a $1 \%$ level. These results accord with the mean TFP efficiency results presented in Fig. 2. The increased significance of year dummies to TFP efficiency may support these estimates being influenced more by unobserved factors emanating from macro and environmental conditions than orientationrestricted technical efficiency measures, since production mix choices that impact TFP efficiency are made before late-season rainfall and yield prospects are known. 


\section{Concluding remarks}

The Debreu-Farrell measure of technical efficiency is widely used to benchmark the performance of agricultural enterprises in both developing and developed countries. The TFP efficiency measure associated with O'Donnell (2008) is an alternative metric for benchmarking performance that measures the ratio of the total factor productivity of a decision-making unit to that of the maximum TFP that is possible in each production period given the available production technology and environment. This study presents an analysis of TFP efficiency as a performance benchmark and compares it to the widely adopted measure of Debreu-Farrell technical efficiency, exposing that gains in technical efficiency may not necessarily yield improvements in firm productivity. We explore the construction of these measures and their application in understanding the relative competitiveness and viability of farm businesses and firms more broadly.

The analysis shows that despite rising agricultural productivity in Western Australia's broadacre farms, as measured by TFP, the average TFP efficiency declined between 2005 and 2011. Our results expose a high frequency with which farm businesses in the sample experienced high technical efficiency yet low and declining TFP efficiency. TFP efficiency estimates vary more than technical efficiency estimates within periods and diverged more over the study period. The multiplicative counterfactual distribution of TFP efficiency components demonstrated that residual mix efficiency is the main driver of TFP efficiency relative to technical or scale efficiency, a finding that is consistent with observation by Tozer and Villano (2013) in the same region.

TFP efficiency and orientation-restricted measures of technical efficiency are found to be largely influenced by different sources of heterogeneity at the farm level, with farm enterprise size shown to be the only significant common driver. Production diversification is found to be positively and significantly associated with both input and output technical efficiency; farm business capital structure is shown have a positive and significant impact on outputoriented technical efficiency. By contrast, off-farm income and location in low rainfall zones are found to be negatively and statistically associated with TFP efficiency only.

The main insight from this study is that firms within a given industry may be technically efficient but not TFP efficient. The determinants of TFP efficiency may also be different from those of technical efficiency. Therefore, intervention policies derived from estimation of primary drivers of technical efficiency may not necessarily be suitable for designing interventions to improve the overall productivity and hence the viability of firms. This is an important observation that researchers and policymakers need to be aware of.

Funding Open Access funding enabled and organized by CAUL and its Member Institutions.

\section{Compliance with ethical standards}

Conflict of interest The authors declare no competing interests.

Publisher's note Springer Nature remains neutral with regard to jurisdictional claims in published maps and institutional affiliations.

Open Access This article is licensed under a Creative Commons Attribution 4.0 International License, which permits use, sharing, adaptation, distribution and reproduction in any medium or format, as long as you give appropriate credit to the original author(s) and the source, provide a link to the Creative Commons license, and indicate if changes were made. The images or other third party material in this article are included in the article's Creative Commons license, unless indicated otherwise in a credit line to the material. If material is not included in the article's Creative Commons license and your intended use is not permitted by statutory regulation or exceeds the permitted use, you will need to obtain permission directly from the copyright holder. To view a copy of this license, visit http://creativecommons. org/licenses/by/4.0/.

\section{References}

ABARES (2012) Australian commodity statistics. Australian Bureau of Agricultural and Resource Economics Statistics, Canberra, Australia

Abdul-Salam Y, Phimister E (2017) Efficiency effects of access to information on small-scale agriculture: empirical evidence from Uganda using stochastic frontier and IRT models. J Agric Econ 68(2):494-517

Adamie BA, Balezentis T, Asmild M (2019) Environmental production factors and efficiency of smallholder agricultural households: using non-parametric conditional frontier methods. J Agric Econ 70(2):471-487

Ang F (2019) Analyzing components of productivity growth using the Bennet-Lowe indicator: an application to Welsh sheep farms. Am J Agric Econ 101(4):1262-1276

Arellano M, Bond S (1991) Some tests of specification for panel data: Monte Carlo evidence and an application to employment equations. Rev Econ Stud 58:277-297

Atsbeha DM, Kristofersson D, Rickertsen K (2017) Animal breeding and productivity of dairy farms. Am J Agric Econ 94 (4):996-1012

Balk B (1998) Industrial price, quantity and productivity indices: the micro-economic theory and an application. Kulwer Academic Publishers, Boston

Ball VE, Hallahan C, Nehring R (2004) Convergence of productivity: an analysis of the catchup hypothesis within a panel of States. Am J Agric Econ 86(5):1315-1321

Ball VE, San-Juan-Mesonada C, Ulloa CA (2014) State productivity growth in agriculture: catching-up and the business cycle. J Product Anal 42(3):327-338

Banker R, Natarajan R, Zhang D (2019) Two-stage estimation of the impact of contextual variables in stochastic frontier production models using data envelopment analysis: second stage OLS versus bootstrap approaches. Eur J Oper Res 278(2):368-384 
Bankwest (2011) Planfarm Bankwest Benchmarks 2010-11. Bankwest, West Perth, Australia

Baráth L, Fertö I (2017) Productivity and convergence in European agriculture. J Agric Econ 68(1):228-248

Baum CF, Schaffer ME, Stillman S (2003) Instrumental variables and GMM: estimation and testing. Stata J 3(1):1-31

Berry CH (1971) Corporate growth and diversification. J Law Econ 14:371-383

Blundell R, Bond S (1998) Initial conditions and moment restrictions in dynamic panel data models. J Econom 87:115-143

Blundell R, Bond S (2000) GMM estimation with persistent panel data: an application to production functions. Econom Rev 19 (3):321-340

Bonfiglio A, Henke R, Pierangeli F, D'Andrea MRP (2020) Effects of redistributing policy support on farmers' technical efficiency. Agric Econ 51:305-320

Briggeman BC (2011) The importance of servicing off-farm income to servicing farm debt. Fed. Reserve Bank of Kansas City Econ. Rev. First Quarter 2011:83-102

Brümmer B, Glauben T, Thijssen G (2002) Decomposition of productivity growth using distance functions: the case of dairy farms in three European countries. Am J Agric Econ 84(3):628-644

Chambers RG, Pieralli S (2020) The sources of measured US agricultural productivity growth: weather, technological change, and adaptation. Am J Agric Econ 102(4):1198-1126

Chambers RG, Pieralli S, Sheng Y (2020) The millennium droughts and Australian agricultural productivity performance: a nonparametric analysis. Am J Agric Econ 102(4): 1198-1226

Chavas JP, Petrie R, Roth M (2005) Farm household production efficiency: evidence from The Gambia. Am J Agric Econ 87 (1):160-179

Dakpo KH, Jeanneaux P, Latruffe L, Mosnier C, Veysset P (2018) Three decades of productivity change in French beef production: a Färe-Primont decomposition. Aust J Agric Resour Econ 59 (1): $1-21$

Daraio C, Simar L, Wilson PW (2018) Central limit theorems for conditional efficiency measures and tests of the "separability" condition in nonparametric, two-stage models of production. Econom J 21(2):170-191

Darku AB, Malla S, Tran KC (2016) Sources and management of agricultural productivity and efficiency in Canadian provinces: crops and livestock. Can J Agric Econ 64(1):49-70

Debreu G (1951) The coefficient of resource utilization. Econometrica 19(2):273-292

Dyson RG, Allen R, Camanho AS, Podinovski VV, Sarrico CS, Shale EA (2001) Pitfalls and protocols in DEA. Eur J Oper Res 132:245-259

Emvalomatis G, Stefanou SE, Oude Lansink A (2011) A reduced-form model for dynamic efficiency measurement: application to dairy farms in Germany and The Netherlands. Am J Agric Econ 93 (1):161-174

ERS (2019) International agricultural productivity: summary findings. https://www.ers.usda.gov/data-products/international-agricultura 1-productivity/summary-findings/ Accessed 20 April 2020

Farrell MJ (1957) The measurement of productive efficiency. J R Stat Soc Ser A 120(3):253-290

Foster L, Haltiwanger J, Syverson J (2008) Reallocation, firm turnover and efficiency: selection on productivity or profitability? Am Econ Rev 98(1):394-425

Gadanakis Y, Stefani G, Lombardi GV, Tiberti M (2020) The impact of financial leverage on farm technical efficiency during periods of price instability. Agric Finance Rev 80(1):1-21

Giannakas K, Schoney R, Tzouvelekas V (2001) Technical efficiency, technological change and output growth of wheat farms in Saskatchewan. Can J Agric Econ 49(2):135-152
Hansen LP (1982) Large sample properties of generalized method of moments estimators. Econometrica 50(3):1029-1054

Hayfield T, Racine JS (2008) Nonparametric econometrics: the np package. J Stat Softw 27(5):1-32.

Hlavac M (2018) Stargazer: well-formatted regression and summary statistics tables. $\mathrm{R}$ package version 5.2.1. https://CRAN.Rproject.org/package $=$ stargazer

Ho TQ, Hoang V, Wilson C, Nguyen T (2017) Which farming systems are efficient for Vietnamese coffee farmers? Econ Anal Policy $56: 114-125$

Islam N, Xayavong V, Kingwell R (2014) Broadacre farm productivity and profitability in south-western Australia. Aust J Agric Resour Econ 58(1): 147-170

Jensen M, Meckling W (1976) Theory of the firm: managerial behavior, agency costs, and ownership structure. J Financ Econ 3 (4):305-360

Julien JC, Bravo-Ureta BE, Rada NE (2019) Assessing farm performance by size in Malawi, Tanzania, and Uganda. Food Policy $84: 153-164$

Kaila H, Tarp F (2019) Can the Internet improve agricultural production? Evidence from Viet Nam. Agric Econ 50:675-691

Karagiannis G, Midmore P, Tzouvelekas V (2004) Parametric decomposition of output growth using a stochastic input distance function. Am J Agric Econ 86(4):1044-1057

Key N (2019) Farm size and productivity growth in the United States Corn Belt. Food Policy 84:186-195

Key N, McBride W (2003) Production contracts and productivity in the U.S. hog sector. Am J Agric Econ 85(3):121-133

Khan MF, Nakano Y, Kurosaki T (2019) Impact of contract farming on land productivity and income of maize and potato growersin Pakistan. Food Policy 85:28-39

Kneip A, Simar L, Wilson PW (2015) When bias kills the variance: central limit theorems for DEA and FDH efficiency scores. Econ Theory 31:394-422

Kneip A, Simar L, Wilson PW (2016) Testing hypotheses in nonparametric models of production. J Bus Econ Stat 34(3):435-456

Komarek AM, Msangi S (2019) Effect of changes in population density and crop productivity on farm households in Malawi. Agric Econ 50(5):615-628

Kostov P, Davidova S, Bailey A (2019) Comparative efficiency of family and corporate farms: does family labour matter? J Agric Econ 70(1):101-115

Kumar S, Russell RR (2002) Technological change, technological catch-up, and capital deepening: relative contributions to growth and convergence. Am Econ Rev 92(3):527-548

Lambarraa F, Stefanou S, Gil JM (2016) The analysis of irreversibility, uncertainty and dynamic technical inefficiency on the investment decision in the Spanish olive sector. Eur Rev Agric Econ 43 (1):59-77

Latruffe L, Nauges C (2014) Technical efficiency and conversion to organic farming: the case of France. Eur Rev Agric Econ 41 (2):227-253

Latruffe L, Bravo-Utera BE, Carpentier A, Desjeux Y, Moreira VH (2017) Subsidies and technical efficiency in agriculture: evidence from european dairy farms. Am J Agric Econ 99(3):783-799

Lawin KG, Tamini LD (2019) Tenure security and farm efficiency analysis correcting for biases from observed and unobserved variables: evidence from Benin. J Agric Econ 70(1):116-134

Leifeld P (2013) texreg: conversion of statistical model output in R to LaTeX and HTML tables. J Stat Softw 55(8):1-24

Li Q, Maasoumi E, Racine JS (2009) A non-parametric test for equality of distributions with mixed categorical and continuous data. J Econom 148(2):186-200

Liang X, Wu Y, Chambers RG, Schmoldt DL, Gao W, Chaoshun L, Liu Y, Sun C, Kennedy JA (2017) Determining climate effects on 
us total agricultural productivity. Proc Natl Aca Sci USA 114 (12):2285-92

Liu Y, Shumwaya CR, Roseman R, Ball VE (2011) Productivity growth and convergence in US agriculture: new cointegration panel data results. Appl Econ 43:91-102

Markowitz H (1952) Portfolio selection. J Finance 7(1):77-91

Mishra AK, Sandretto CL (2002) Stability of farm income and the role of nonfarm income in U.S. agriculture. Rev Agric Econ 24(1):208-221

Mishra AK, Rezitis AN, Tsionas MG (2019) Estimating technical efficiency and production risk under contract farming: a Bayesian estimation and stochastic dominance methodology. J Agric Econ 70(2):353-371

Mishra AK, Rezitis AN, Tsionas MG (2020) Production under input endogeneity and farm-specific risk aversion: evidence from contract farming and Bayesian method. Eur Rev Agric Econ 47 (2):591-618

Mugera AW, Langemeier MR (2011) Does farm size and specialization matter for productive efficiency? Results from Kansas. J Agric Appl Econ 43(4):515-528

Mugera AW, Nyambane GG (2014) Impact of debt structure on production efficiency and financial performance on Broadacre farms in Western Australia. Aust J Agric Resour Econ 56(1):1-17

Mugera AW, Langemeier MR, Featherstone AM (2012) Labor productivity convergence in the Kansas farm sector: a three-stage procedure using data envelopment analysis and semiparametric regression analysis. J Product Anal 38(1):63-79

Mugera AW, Langemeier MR, Ojede A (2016) Contributions of productivity and relative price changes to farm-level profitability change. Am J Agric Econ 98(4):1210-1229

Murtaza G, Thapa GB (2017) Factors affecting technical efficiency of small-scale apple farms in Balochistan Plateau, Pakistan. J Mt Sci 14(4):782-794

Newman A, Matthews C (2006) The productivity performance of Irish dairy farms 1984-2000: a multiple output distance function approach. J Product Anal 26(2):191-205

Njuki E, Bravo-Ureta BE, O’Donnell CJ (2018) Decomposing agricultural productivity growth using a random-parameters stochastic production frontier. Empir Econ 57:839-860

Njuki E, Bravo-Ureta BE, O'Donnell CJ (2018) A new look at the decomposition of agricultural productivity growth incorporating weather effects. PLoS One 13(2):e0192432. https://doi.org/10. 1371/journal.pone.0192432

Nordjo RE, Adjasi CKD (2019) The impact of credit on productivity of smallholder farmers in Ghana. Agric Finance Rev 80(1):91-109

O'Donnell CJ (2010) Measuring and decomposing agricultural productivity and profitability change. Aust J Agric Resour Econ 54 (4):527-560

O'Donnell CJ (2011) DPIN 3.0: A program for decomposing productivity index numbers. The University of Queensland Centre for Efficiency and Productivity Analysis, Queensland, Australia

O'Donnell CJ (2012a) An aggregate quantity framework for measuring and decomposing productivity change. J Product Anal 38 (2):255-272

O'Donnell CJ (2012b) Nonparametric estimates of the components of productivity and profitability change in U.S. agriculture. Am J Agric Econ 94(4):873-891

O’Donnell CJ (2016) Using information about technologies, markets and firm behaviour to decompose a proper productivity index. $\mathrm{J}$ Econom 190(2):328-340

O’Donnell CJ (2018) Productivity and efficiency analysis: an economic approach to measuring and explaining managerial performance. Springer Nature, Singapore

O’Donnell CJ (2008) An aggregate quantity-price framework for measuring and decomposing productivity and profitability change. Centre for Efficiency and Productivity Analysis Working Papers No. WP07/2008, University of Queensland, 2008
Ogundari K (2013) Crop diversification and technical efficiency in food crop production: A study of peasant farmers in Nigeria. Int $\mathrm{J}$ Soc Econ 40(3):267-287

Oude Lansink A, Silva E, Stefanou S (2000) Decomposing productivity growth allowing efficiency gains and price-induced technical progress. Eur Rev Agric Econ 27(4):497-518

Pede VO, Areal FJ, Singbo A, McKinley J, Kajisa K (2018) Spatial dependency and technical efficiency: an application of a Bayesian stochastic frontier model to irrigated and rainfed rice farmers in Bohol, Philippines. Agric Econ 49:301-312

Planfarm Bankwest (2013) Planfarm Bankwest Benchmarks 20122013. Planfarm Pty Ltd and Bankwest Agribusiness Centre, Perth

Plastina A, Lence SH, Ortiz-Bobea A (2021) How weather affects the decomposition of total factor productivity in U.S. agriculture. Agric Econ 52(2): 215-234

Poudel BN, Paudel KP, Zilberman D (2011) Agricultural productivity convergence: myth or reality? J Agric Appl Econ 43(1):143-156

Qushim B, Gillespie J, McMillin K (2016) Meat goat enterprise efficiency analysis in the southeastern United States. J Agric Appl Econ 48(1):52-72

Rada N, Fuglie KO (2019) New perspectives on farm size and productivity. Food Policy 84:147-152

Rada N, Helfand S, Magalhães M (2019) Agricultural productivity growth in Brazil: large and small farms excel. Food Policy 84:176-185

Rada N, Liefert W, Liefert O (2020) Evaluating agricultural productivity and policy in Russia. J Agric Econ 71(1):96-117

Rahman S (2009) Whether crop diversification is a desired strategy for agricultural growth in Bangladesh? Food Policy 34(4):340-349

Reimers M, Kaslan S (2012) Revisiting the role of education for agricultural productivity. Am J Agric Econ 95(1):131-152

Roll KH (2019) Moral hazard: the effect of insurance on risk and efficiency. Agric Econ 50:367-375

Sabasi D, Shumway CR, Astill GM (2019) Off-farm work and technical efficiency on U.S. dairies. Agric Econ 50(4):379-393

Sala-i-Martin XX (1996) The classical approach to convergence analysis. Econ J 106(437):1019-1036

Scheiterle L, Häring V, Birner R, Bosch C (2019) Soil, Striga, or subsidies? Determinants of maize productivity in northern Ghana. Agric Econ 50(4):479-494

Shee A, Stefanou SE (2015) Endogeneity corrected stochastic production frontier and technical efficiency. Am J Agric Econ 97 (3):939-952

Sheng Y, Davidson A, Fuglie K, Zhang D (2016) Input substitution, productivity performance and farm size. Aust J Agric Econ 59 (1): $1-21$

Silva E, Stefanou SE (2007) Dynamic efficiency measurement: theory and application. Am J Agric Econ 89(2):398-419

Simar L, Zelenyuk V (2018) Central limit theorems for aggregate efficiency. Oper Res 66(1):137-149

Simar L, Zelenyuk V (2020) Improving finite sample approximation by central limit theorems for estimates from Data Envelopment Analysis. Eur J Oper Res 284:1002-1015

Skevas I, Emvalomatis G, Brümmer B (2018b) The effect of farm characteristics on the persistence of technical inefficiency: a case study in German dairy farming. Eur Rev Agric Econ 45 (1):3-25

Skevas I, Emvalomatis G, Brümmer B (2018a) Productivity growth measurement and decomposition under a dynamic inefficiency specification: the case of German dairy farms. Eur J Oper Res 271 (1):250-261

Solís D, Bravo-Utera BE, Quiroga R (2009) Technical efficiency among peasant farmers participating in natural resource management programmes in Central America. J Agric Econ 60 (1):202-219

Suhariyanto K, Thirtle C (2001) Asian agricultural productivity and convergence. J Agric Econ 52(3):96-110 
Thompson W, Dewbre J, Pieralli S, Schoreder K, Domínguez IP, Westhoff P (2019) Long-term crop productivity response and its interaction with cereal markets and energy prices. Food Policy $84: 1-9$

Tozer P, Villano R (2013) Decomposing productivity and efficiency among Western Australian grain producers. J Agric Resour Econ 38(3):312-326

Wickham H, François R, Henry L, Müller K (2021) dplyr: a grammar of data manipulation. $\mathrm{R}$ package version 1.0 .5 . https://CRAN.Rproject.org/package $=$ dplyr

Windmeijer F (2005) A finite sample correction for the variance of linear efficient two-step GMM estimators. J Econometrics 126:25-51
Wooldridge J (2001) Applications of generalized moment of methods estimation. J Econ Perspect 15(4):87-100

Yee J, Ahearn MC, Huffman W (2004) Links among farm productivity, off-farm work and farm size in the Southeast. J Agric Appl Econ 36(3):591-603

Zelenyuk V (2020) Aggregation of inputs and outputs prior to Data Envelopment Analysis under big data. Eur J Oper Res 282 (1):172-187

Zhengfei G, Oude Lansink A (2006) The source of productivity growth in Dutch agriculture: a perspective from finance. Am J Agric Econ 88(3):644-656 